\title{
Ischemic Stroke and Subarachnoid Hemorrhage following Epstein-Barr Virus Infection
}

\author{
Jonathan Rios ${ }^{1}$ Catarina Félix ${ }^{2}$ Paula Proença ${ }^{3}$ \\ ${ }^{1}$ Department of Physical Medicine and Rehabilitation, Algarve \\ Hospital University Center-Faro, Portugal, Rua Leão Penedo, \\ Faro, Portugal \\ 2Department of Neurology, Algarve Hospital University \\ Center-Faro, Portugal, Rua Leão Penedo, Faro, Portugal \\ 3 Infectious Disease Department, Algarve Hospital University \\ Center-Faro, Portugal, Rua Leão Penedo, Faro, Portugal \\ ${ }^{4}$ Department of Physical Medicine and Rehabilitation, Algarve \\ Hospital University Center-Faro, Portugal, Rua Leão Penedo, \\ Faro, Portugal \\ ${ }^{5}$ Department of Biomedical Sciences and Medicine, University of \\ Algarve-Edifício 7-Ala Nascente- $3^{\circ}$ andar Campus de Gambelas \\ Faro, Portugal
}

J Neurosci Rural Pract 2020;11:680-682

\begin{abstract}
Address for correspondence Hipólito Nzwalo, MD, MSc, PhD, Department of Biomedical Sciences and Medicine, University of Algarve-Edifício 7-Ala Nascente- $3^{\circ}$ andar Campus de Gambelas 8005-139 Faro, Portugal (e-mail: nzwalo@gmail.com).
\end{abstract}

The epidemiological link between inflammation, infection, and acute ischemic stroke (AIS) is well known. ${ }^{1}$ Transient prothrombotic status and vasculitis are possible explanatory factors. ${ }^{1}$ Aneurysm formation in association with central nervous system infections is occasionally reported. ${ }^{2}$ Ischemic or hemorrhagic complication in relation to neurotropic virus infections, including Epstein-Barr Virus (EBV) are rarely reported in adults. Thus, we report here an extremely rare case of ischemic and hemorrhagic cerebrovascular complications in the context of EBV neuroinfection.

A 31-year-old previously healthy male was admitted to the emergency room with a 2-week history of progressive headache, malaise, and fever. On the admission day, he awakened with severe headache, photophobia, vertigo, and unstable walk. He was somnolent but oriented and collaborative; had neck stiffness; right-sided Horner's syndrome with ocular flutter; loss of facial pain and temperature sensation and hemiparesis (grade 4 in the Medical Research Council evaluation); left-sided hypoesthesia (pain and temperature); and trunk and gait ataxia (Opalski's syndrome). The rest of the neurological and general examination was unremarkable. The workup revealed leukocytosis $(14,200$ cells/L) and high $(172 \mathrm{mg} / \mathrm{dL}) \mathrm{C}$-reactive protein. Platelets, coagulation, and bleeding times were within normal reference values. The cerebrospinal fluid (CSF) showed neutrophilic pleocytosis (60 cells $\left./ \mathrm{mm}^{3}\right), 49 \mathrm{mg} / \mathrm{dL}$ of proteins, and serum CSF/ glucose ratio of 0.3. Magnetic resonance imaging (MRI) of the brain revealed the presence of right postero-lateral-inferior protuberance and bulbar infarction $(-$ Fig. 1A-C). The angio-MRI and cervical vessel Doppler ultrasound was normal. Initial serology of EBV virus was positive for VCA (viral capsid antigen) $\operatorname{IgM}(31.1 \mathrm{UA} / \mathrm{mL})$ and VCA $\operatorname{IgG}(33.3 \mathrm{UA} / \mathrm{mL})$ and negative for Epstein-Barr nuclear antigen (EBNA) IgG. He started with acyclovir and ceftriaxone. Due to the presence of antiphospholipid syndrome (positive lupus anticoagulant and anticardiolipin antibodies), a decision to start dabigatran was taken (off-label use). The results from the microbiological study and extensive autoimmune panel were negative. He progressively improved and returned to work 4 weeks later. Total 6 weeks after hospital discharge, he was readmitted after sudden intense occipital headache followed by progressive decrease of the level of consciousness. The brain cranial tomography revealed the presence of perimesencephalic subarachnoid hemorrhage (SAH; - Fig. 1D-F). The angiography documented the presence of distal right posterior inferior cerebellar artery (PICA) aneurism which was successfully surgically treated. On post-surgery, he was conscious, oriented, and collaborative; had horizontal-rotatory nystagmus with fast phase to the right side; mild left pain, temperature, proprioceptive hypoesthesia; and severe gait ataxia. On follow-up study, the antiphospholipid antibodies became negative and the serological tests-CA IgM negative; EBNA IgG positive (3.6 UA/mL), and VCA IgG levels drop (28.2 UA/mL) confirming the acute EBV virus infection. With intensive rehabilitation, he improved, and apart from pain and thermal hypoesthesia, the neurological examination was normal after 3 months of SAH.

We present rare case of sequential occurrence of EBV meningoencephalitis, AIS followed by SAH. Serological testing remains the most commonly diagnostic tool for EBV infection and negative CSF virus does not exclude neuro-infection. ${ }^{3}$ The acute infection induced prothrombotic status and the transient secondary antiphospholipid antibody syndrome, probably contributed the occurrence of 

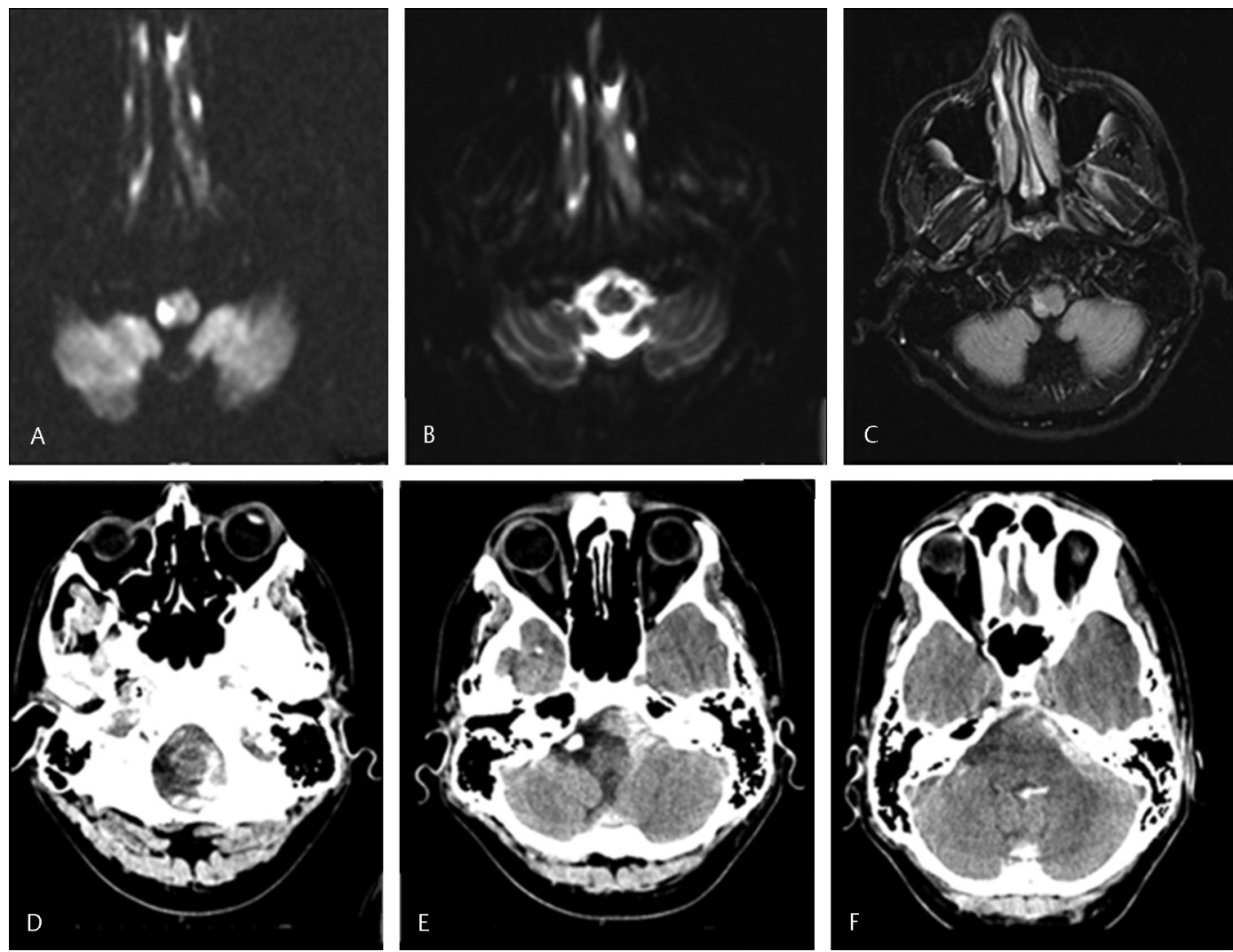

Fig. 1 Brain magnetic imaging resonance $(\mathbf{A}-\mathbf{C})$ showing the presence of small postero-lateral right medulla ischemic stroke-hyperintensity on the diffusion imaging (A) with corresponding hypointensity on the ADC map (B) and hyperintensity on the fluid attenuated inversion recovery $(\mathbf{C})$, brain computed tomography $(\mathbf{D}-\mathbf{F})$ showing the presence of peri-mesencephalic subarachnoid hemorrhage.

AIS in our patient. It is reasonable to consider that the prothrombotic status may had caused artery to artery thromboembolism from the preexistent dominant right PICA aneurysm precipitating the occurrence of AIS. Of relevance is also the presence of Opalski's syndrome, an extremely rare variant of lateral-medullary syndrome defined in our patient by the presence of ipsilateral right-sided cranial nerve and pyramidal signs. Our patient had the supporting characteristics of a mycotic aneurysm: meningitis in the previous 4 weeks, age less than 44 , distal located aneurysm, and recent lumbar puncture. ${ }^{4}$ Therefore, the occurrence of SAH could also be secondary to the rupture of an underlying infectious or mycotic aneurysm. Our patient was using a direct oral anticoagulant at the time of SAH. Although anticoagulants contribute to SAH severity, they are not clearly associated with an increased risk for aneurysm rupture..$^{5}$ Few cases of intracranial hemorrhage associated with EBV infection, almost exclusively arising from brain parenchyma, have been published so far. ${ }^{6,7}$

Despite the sequence of severe neurological conditions and the functional impairment, intensive rehabilitation allowed autonomy 3 months later. In conclusion, this case illustrates the rare co-occurrence brainstem ischemic stroke and perimesencephalic aneurysmatic SAH from a PICA aneurysm in a context of acute EBV infection. We assumed that these two cerebrovascular complications were probably interrelated.

\section{Funding}

None.

\section{Conflict of Interest}

None declared.

\section{References}

1 Lindsberg PJ, Grau AJ. Inflammation and infections as risk factors for ischemic stroke. Stroke 2003;34(10):2518-2532

2 Arauz A, Ruiz-Navarro F, Silos H, et al. Concurrent asymptomatic inflammatory aneurysm and ischemic stroke due to cysticercal arteritis. Clin Neurol Neurosurg 2013;115(12):2540-2542

3 De Paschale M, Clerici P. Serological diagnosis of Epstein-Barr virus infection: Problems and solutions. World J Virol 2012;1(1):31-43

4 Kannoth S, Thomas SV, Nair S, Sarma PS. Proposed diagnostic criteria for intracranial infectious aneurysms. J Neurol Neurosurg Psychiatry 2008;79(8):943-946

5 Williams LN, Brown RD Jr. Management of unruptured intracranial aneurysms. Neurol Clin Pract 2013;3(2):99-108

6 Sabat S, Agarwal A, Zacharia T, Labib S, Yousef J. Epstein-Barr virus encephalitis presenting as cerebellar hemorrhage. Neuroradiol J 2015;28(6):555-558

7 Ascenção BB, Gonçalves AC, Luís N, Sá J, Brito AP, Poças JM. Epstein-Barr virus hemorrhagic meningoencephalitis: case report and review of the literature. J Neurovirol 2016;22(5):695-698 